\title{
2
}

\section{The Anthropology of Fallout}

The culture of any society at any moment is more like the debris, or "fallout," of past ideological systems, than it is itself a system, a coherent whole.

-Victor Turner

"I always thought that anthropologists studied the skulls they dug out of the ground instead of the skulls that were still walking around," one resident of Seneca County teased me while we were discussing my project to study the events that had taken place in his community. Many of his neighbors agreed that an anthropologist didn't seem the appropriate person to study their community. "Some of us were talking," one law enforcement officer explained, "and we were trying to figure out what anthropology is." He explained that they could understand that some anthropologists dug up old bones (he had worked with some physical anthropologists on murder cases) and that some dug up old civilizations, but didn't all the other kinds of anthropologists work in places like Africa?

It is not surprising that Seneca County residents were confused by the idea of an anthropologist studying a contemporary U.S. community. Like many who call anthropology their profession, this general public associates anthropology with archaeological excavations, with the physical anthropologist's search for the remains of evolutionary precursors, or with the study of non-Western, nonindustrialized societies. Anthropology retains for the initiated as well as the uninitiated an association with the study of the exotic, the esoteric, and the other.

Yet thinking of anthropology this way-as a discipline concerned only 
with people and things distant in time, place, and habit-belies anthropology's history, its present-day circumstances, and its applicability to the events in Seneca County in I983. Actually, anthropology never exclusively focused on the untouched, unstudied "primitive" society idealized as the object of anthropological inquiry. Such researchers as Margaret Mead, Cora Du Bois, Marvin Harris, Hortense Powdermaker, Jules Henry, Evon Vogt, John Bennett, Constance Perin, Herve Varenne, and David Schneider are prominent in a rich tradition of American studies. Anthropology has always studied culture contact, contemporary societies, the West and the rest, and the nonindustrialized as well as the overindustrialized.

Today, for a variety of practical, ethical, political, and theoretical reasons, American anthropology no longer wants or needs to be seen as primarily studying the "primitive" other. Practically speaking, the extensive influence of global industrial, cultural, technological, and informational practices means that the so-called pristine, isolated societies that anthropology thought it needed to seek for analysis now exist only in anthropological nostalgia. In addition, the extensive post-World War II development of new nation-states has not only blurred the lines between groups that had previously been considered culturally and politically distinct but has also created economic and military conditions that make fieldwork in many parts of the world impractical. Access to subject societies is thus often not financially feasible or safe for anthropologists.

Ethical and political considerations have been influenced by the ability of former anthropological subjects to gain access to the same universities that have trained generations of anthropologists. Former subjects are discovering the need and desire to study themselves from their own perspectives and not to rely on Western interpretations of their lives, which have been criticized for their colonialist or neocolonialist bent. Many anthropologists came to share the concern of formerly colonized and studied peoples that anthropology was implicated in colonialism. They began to rethink the anthropological project, particularly after the temporary radicalization of academia in the 1960 s and the revelation that anthropologists had collaborated in counterinsurgency against indigenous peoples in Indochina and Latin America by gathering anthropological data to be used against them (Marcus and Fischer 1986:35). The questions of whom we should study, why we should study them, and what we do with the information we collect have helped redirect anthropological projects.

In American anthropology, for many reasons, theoretical shifts have been quite complex in recent years. Interest has increased in interdisciplin- 
ary study; the use of textual analogies; the analysis of class, race, and gender; and emphasis on conflict and change instead of rules and consistencies. In consequence, anthropology has been opened to new subjects, new methodologies, and new theoretical possibilities. For some anthropologists, the changes have meant closer alliances with the biological and physical sciences and with statistical, quantitative, and computer analyses. Others have found their new allies in the humanities and the interpretive sciences. My work is aligned with theirs. Like them, I am interested in how literary criticism, the new historiography, revisions in psychoanalytic theory and the many facets of feminist studies can expand the horizons of anthropology. With these anthropologists, I am involved in crossing or redrawing disciplinary boundaries, exploring how to revamp our way of thinking altogether.

The changes due to the increased emphasis on interdisciplinary connections have resulted in what Clifford Geertz has called a blurring of genres or disciplines. Something is happening "to the way we think about the way we think" says Geertz (I 983:20), and one grounding for this transdisciplinary, humanities-oriented work is the shift from the use of mechanistic or organic analogies to textual ones. Literary criticism has now become a major influence on anthropological inquiry. As George Marcus and Michael Fischer tell us (1986:5), "Theoretical developments in the field of literary criticism and interpretation ha[ve] replaced linguistics as an influential source of new ideas about theory and methodology in anthropology." Certain subfields of anthropology-notably symbolic, interpretive, feminist, and psychological anthropology—have been most open to these influences.

What is this textual analogy and what does it offer anthropology? Anthropology readily admits that access to such cultural features as identity, community, belief, motivation, or interpretive strategies cannot be direct. We cannot see a motivation or a plan; we can see only their effects-how people act, what they say and don't say about what they do, what they produce and consume. As anthropologists have long been aware, aspects of culture, indeed "culture" itself, are mediated, and anthropology's job has been to make sense of culture from the traces it leaves behind. Some anthropologists have approached the problem of mediated, indirect access to "culture" by defining culture as if it were a kind of text. According to this textual approach, "social actions can be 'read' for their meanings by the observer just as written and spoken materials more conventionally are" (Marcus and Fischer $1986: 26$ ). What is studied in this approach is not so much "life itself" as texts and performances about life. 
Still, if this "culture-as-text" approach has been stimulating for anthropologists, it has also created some dangerous traps that are just beginning to be recognized. Text building is a major social activity, not confined to any one type of person but produced by everyone. As Shirley Nelson Garner, Claire Kahane, and Madelon Sprengnether remark, "The stories we tell ourselves about who we are or hope to be play a primary role in creating and sustaining our identities as we move through an uncertain world" (1985:9). Gayatri Spivak (1987:95) suggests that seeing life as a text is not simply an abstract invention of social scientists but parallels the way people actually conduct their lives. Texts are read and interpreted in a variety of ways and the particular method one chooses for reading depends on a methodological orientation or interpretive strategy. Texts can be seen, for example, as stable entities that contain their own meaning or, alternatively, as contested forms with negotiated meanings. Between these two poles are a whole range of strategies that radically alter the textual project. The danger for anthropology is in choosing a conservative strategy that tries to limit the possible range of meanings for a text rather than one that encourages a wide play of meanings and interpretations. Some anthropologists (inappropriately, I believe) have used the textual analogy to suggest that a text/culture need only be properly read in order for the correct and accurate interpretation of the text/culture to become clear (that is, for the meaning of the text/culture to be evident).

Like the now-unfashionable New Critics, who perceived the literary text as a stable source of meaning, anthropologists who see the text as representation of reality approach it as directly reflecting or embodying the culture that made it. Taking a "functional" attitude, they see the text as essentially coherent and integrated, its stable and definitive meaning available after a close, careful reading that tends to concentrate on the symbols and tropes (figures of speech such as metaphors) of the independent and self-sufficient text. The New Critics took the text as a coherent object that could be read apart from its cranky author or the peculiarities of a particular reader. The anthropological equivalent of the New Critics may have been the structural-functionalists, who were concerned with formal, idealized qualities and how they were integrated in a culture.

In the structural approach to textual analysis (both literary criticism and anthropology are indebted to Claude Lévi-Strauss here), texts were seen not as independent forms but as examples of recurring narrative and social patterns and themes. Structural analysis, as originally developed, "sought to reconstitute a common language for all narratives," according to Josué Harari (1979:23). This concentration on the form rather than 
just the content of the text was the hallmark of structuralism; the content could be changed but the structure could remain the same as long as the "relations between units is preserved," wrote Terry Eagleton (I983:95). Structuralism also introduced the notion of conflict into the text when it tried to delineate the binary oppositions (hot/cold, nature/culture, male/ female) underpinning the narrative. It showed how these binary oppositions (which it tended to see as universal structures of the mind) determined the stable and identifiable meaning of the text.

Poststructuralists have challenged this model in recent years. If structuralists "are convinced that systematic knowledge is possible," as Jonathan Culler notes, then "post-structuralists claim to know only the impossibility of this knowledge" ( $1982: 22$ ). Criticism of structuralism, particularly for its notion of universal narrative structures as inherent elements of the human mind, does not entirely negate its potential contribution to textual methodology for anthropology. Structuralism did suggest the importance of seeing texts as constructed rather than as a reflection of external reality. What poststructuralism attempts to do is push this constructedness to the forefront without attributing it either to universals of the human psyche or to individual creative action.

The poststructuralist approach sees meaning not as residing in the text but as a function of the complexity of language and a product of the interaction of textual form, content, production and reception. Deconstruction is one such poststructural strategy, whose goal is to undermine the seeming stability of the text by showing that in order to posit one meaning, a text necessarily has to repress others. Deconstruction shows how the text itself contains the information to undermine the meaning that it is at the same time trying to promote. A text can be neither mined for its symbolic, hidden meaning nor categorized by its structure, form, content, or theme. Instead, deconstruction points out the contradictions in a text's logic and content. It is interested in the binary oppositions of structuralism, but it "tries to show how such oppositions, in order to hold themselves in place, are sometimes betrayed into inverting or collapsing themselves" (Eagleton 1983:133).

Feminist criticisms (of which there are many forms) can be seen as another strategy that attacks one of the most pervasive and oppressive structuralist binary oppositions-that between male and female. Feminist critics question not just the male and female roles seen in a text but also the general notion of dividing people into such rigid categories and power relations. They are concerned with the constraints on textual production that arise because of gender relations, and they believe it is crucial to place 
a text in the larger context of such relations, which profoundly affect its reading and writing. In this view, texts do not reflect an inherent biological gender nature; they have been constructed to support a particular politically motivated image of male and female.

Traditional psychoanalysis enacted an odd analyst-patient relationship with texts, attempting to identify the "unconscious" themes ruling a textual construction. More recent revisions in psychoanalytic theory (particularly those drawing on the work of Jacques Lacan and Jacques Derrida) look at how texts attempt (and fail) to control their own readings. In its concern for the style of repression a text uses to reveal and conceal what it does, current psychoanalytic thinking shows the inherent ambiguity and unresolvable conflicts residing in all texts. Lacanian analysis looks at how language and texts constitute us as subjects, and it refuses to let either our own reading of the text or the reading of ourselves remain stable. Since psychoanaly sis studies the "internalisation of the social in the formation of the individual," as Victor Burgin puts it (1986:40), it can be useful for textual anthropology in relating text, society, and the individual.

What revisionary textual strategists (poststructuralists, feminists, deconstructionists, and Lacanian psychoanalysts) are pointing out is that it is necessary to avoid stabilizing the meaning of texts, behaviors, and events and always to consider the politics surrounding textual production and reception. It is the play of meanings resulting from the interaction of text, textual production, and textual reception that makes textual analogy useful for the field of anthropology.

The notion that texts are continually negotiated and always wrapped up in the intrigues of representation is useful for anthropology because it reminds us that texts are not only structures of meaning but also structures of power. "No reading is innocent," Susan Rubin Suleiman tells us, because "every reading is an interpretation, and every interpretation is an appropriation of the text for its own purpose" (I986:I22). Every society tries to organize and control the ways that events, people, and objects are perceived, interpreted, reacted to, and acted upon. This system of control and relations is called discourse. Discourse is concerned with setting limits on how people talk and interpret by the establishment of a set of shared expectations about what things mean.

A discourse, writes Mark Philp, is "a system of possibility for knowledge ... what rules permit certain statements to be made; what rules order these statements; what rules permit us to identify some statements as true and some as false; what rules allow the construction of a map, model, or 
classificatory system; what rules allow us to identify certain individuals as authors; and what rules are revealed when an object of discourse is modified or transformed. . . When sets of rules of these kinds can be identified, we are dealing with a discursive formation or discourse" (Philp I 986:68-69). As a system of possibilities, discourse is used by individuals in their social relations, but it may or may not be used consciously: in most cases it operates "behind the backs" of the social actors (ibid.). Michel Foucault suggests that an analysis of discourse should consider not only how actors are constrained by discourse and in turn challenge it but also the modes of "circulation, valorization, attribution, and appropriation of discourses" (Foucault 1979: 5 8). As we look for these discursive rules in a particular setting, we can see the relation among various social actors, between individuals and groups, and between community members and the larger system that contains and articulates their discursive fields.

Discourse, according to Edward Said, "is not mere formalization of knowledge; its aim is the control and manipulation of knowledge, the body politic, and ultimately the State" (1978b:678). Whoever can control, convince, or seduce others into accepting a particular discourse is exercising power by controlling interpretations and the social behavior influenced by them. The strategies of power acts are revealed in a discourse analysis, for discourse lays out the possibilities and the boundaries of choice and action in particular power relations.

Some discourses are dominant or more authoritative and have a greater chance of exercising this power. The authoritative discourse is the "already uttered" prior discourse that is backed by legal, political, and moral authority. It enjoys a privileged position because it dominates official public performance, expresses the established position, and "sees itself as giving the correct interpretation" (Bruner and Gorfain 1984:59). Challenges to the dominant discourse always appear to be coming from the margins of society, as if they were voices that were "other." Edward Bruner and Phyllis Gorfain explain that "authoritative voices attempt to fix meanings and stabilize order, whereas challenging voices question established meanings and tend to be deconstructive" (ibid.:56).

A text must make its own discursive features seem natural and normal and those of the challenging discourse seem perverted and absurd. Discourse analysis assumes that a text produced within a specific discourse tries to hide its workings and its mechanisms in order to maintain this facade of normalcy and naturalism. It seeks to uncover these workings, to show how the discourse works to manipulate knowledge, to persuade its adherents, to define itself as natural and true, and to stimulate people to 
social action. But discourse analysis, especially when used in anthropology, requires us to consider not only how these texts are constructed but how they are actually used and what effects they have when they are brought into the public arena. How a text is experienced affects its interpretations and reception; in fact, the text has no meaning until it is put into circulation, and it is these circulating, flexible, and ever-changing readings of texts that should concern the anthropologist.

Since anthropology sees "people as active agents in the historical process who construct their own world" (Bruner I986a:I2), rather than implementers of a predetermined textual strategy, we need to see how people do things with texts, not just how they articulate and read them. As active agents in the production, reading, resistance to, and reinterpretation of texts, people are neither dupes of discourse nor free-wheeling agents of action and power. Rather, they are conflict-ridden actors, simultaneously confident and uncertain, bold and reticent in their production of meaning. This aspect of agency is what is generally missing from many nonanthropological textual analyses and also from many of the anthropological ones.

The emphasis on textuality coincides with another change in anthropological inquiry. Anthropology (as well as other disciplines) has shifted emphasis from harmony models to conflict models. Anthropologist Victor Turner has called this adjustment the "postmodern turn" (1979:66). It leaves behind the traditional emphasis on the delineation of sociocultural rules in favor of exploring a society's practices and performances, seeking "in the very flaws, hesitations, personal factors, incomplete, elliptical, context-dependent, situational components of performance, clues to the very nature of human process itself" (ibid.:66-67). It is a change from trying to predict behavior, prove cause and effect, and determine origins toward trying to understand, explicate, and interpret without closing off other readings of textual materials.

Earlier anthropologists were not unaware of the conflicts and contradictions that existed in social life; as Sally Moore notes, they "chose ... to ignore them in order to concentrate on the element of order" (I975:2 I6). Moore explains that in the development of what is often called the practice approach, "there has been a shift of emphasis from the study of normative models to the study of specific situations and specific sequences of events . . f full of inconsistencies, oppositions, contradictions, and tensions" (ibid.).

Many factors contributed to the disillusionment with the social harmony theories and their static models of analysis. Among them were Freudian theories of motivational ambivalence and the inevitability of 
psychic conflict in human development. More recently, linguistics, always a source of inspirations and theoretical trends for anthropology, shifted its interests from the langue, or grammar, aspect of Ferdinand de Saussure's model of language to the parole, or speech/performance aspect. LéviStrauss's structuralist application of this linguistic model, with its emphasis on uncovering the underlying langue, or structures, of sociocultural data, has given way to a sociolinguistic emphasis on parole, or speech, which is studied not only in relation to the rules of the language but also in relation to its social context and performative features.

Inherent social conflict, especially as expressed in symbolic behavior, is a central theme of the influential work of Victor Turner. According to Turner, ritual is the place where conflict is acknowledged, the place where a society delineates the things that did not work and the steps necessary for a tentative and somewhat temporary social reconsolidation (Turner I967). It is in ritual that a society has the most to say about itself, and what it is talking about is conflict. Conflict is thus not necessarily a destructive force but rather the means by which some form of continuity can be achieved. In fact, Turner points out, this continuity is difficult without the conflict that allows people to reemphasize and recreate the social categories that define and give meaning to their lives. Texts are produced in this atmosphere of conflict, out of a desire to understand and resolve the contradictions of social life. They are not the storage place for stable and shared meanings but the sites at which we can see meanings in conflict.

The postmodern turn in anthropology also promotes a shift in subject matter, or as Hal Foster tells us, "The mandate of postmodernism is also: "change the object itself" " ( $1983: \mathrm{x}$ ). This mandate, combined with one that instructs anthropologists to be self-reflexive, has led to a change in the cultures studied. Now when anthropology studies the other, it is often in relation to the self, "while seeing itself as other" (Clifford I 986:23). Some anthropologists have turned to analysis of the "American" or United States culture that has nurtured and educated them and necessarily provides the context for all their work. This anthropology at home has created a whole range of new subjects, including the ones considered in this book.

Many of the early American studies focused on either of two entitiesthe local community or the national culture. There was less interest in explicating the relationship between the two. A postmodern analysis can help here because it will reify neither the local identities nor the national ones. Whether we like it or not, says Paul Rabinow, we all share "a specificity of historical experiences and place, however complex and con- 
testable they may be, and a world-wide macro interdependency encompassing any particularity" (1986:258). We live in a state of "cosmopolitanism" no matter where we reside-in the biggest city or the smallest rural hamlet. We live "in-between," in what Turner would call a liminal state. It is this in-between state, this negotiation between the local and the national/global that is the subject of the postmodern study of American "culture."

We can approach the study of this liminal state by looking at moments of exchange and negotiation between local discourses and events and the more widely available national discursive and symbolic formations. Local discourses are readable in all the familiar places: in behavior, events, ritual, language, local texts, and local history. National discourses, because they are mass discourses, are available to us through aspects of the mass culture of late twentieth-century patriarchal, capitalist-consumer society: in national symbols, advertising images, high culture, and the mass-media texts of television, motion pictures, and the popular arts.

The line between what George Marcus calls the "local world of subjects and the global world of system" (I986:I7I) blurs as we apply a critique of representation and textuality to it because the local situation is framed by a simultaneous resistance to and accommodation of larger discourses. Microdiscourses, the local organization of knowledge which highlights certain meanings and deemphasizes others in order to achieve coherence, are reciprocally related to macrodiscourses. The local selects and promotes aspects of the general, while the general supplies ideological representations that can be used to legitimate and organize the local constructions and the resulting distribution of power and status (Chilton 1985:xvi).

The problem, suggest George Marcus and Michael Fischer, is "how to represent the embedding of richly described local cultural worlds in larger, impersonal systems of political economy" if "outside" forces are part of the construction of the local "inside" world ( $1986: 77$ ). How a local world simultaneously processes its own "culture" and that which is thrown at it from outside and above is one of the major concerns of this book. I do not look for large metanarratives to explain the events under consideration, but I use the postmodern strategy of discursive and textual analysis to evoke a sense of life during a series of inter- and intracommunity conflicts. But beyond just evoking these events, I hope to provide a strategy for analyzing how these events are constructed and interpreted locally and globally and for delineating the effects of these practices on people's lives and on the representations they create about those lives. 